\title{
Epidemiology of stage III lung cancer: frequency, diagnostic characteristics, and survival
}

\author{
Ana Casal-Mouriño ${ }^{1,2}$, Alberto Ruano-Ravina ${ }^{2,3}$, María Lorenzo-González ${ }^{2,4}$, Ángeles Rodríguez-Martínez ${ }^{2,5}$, \\ Alexandra Giraldo-Osorio ${ }^{2,6}$, Leonor Varela-Lema ${ }^{2,7}$, Tara Pereiro-Brea ${ }^{2,8}$, Juan Miguel Barros-Dios ${ }^{2}$, \\ Luis Valdés-Cuadrado ${ }^{1,9}$, Mónica Pérez-Ríos ${ }^{2,3}$
}

${ }^{1}$ Department of Pneumology, Santiago de Compostela University Clinical Teaching Hospital, Galicia, Spain; ${ }^{2}$ Department of Preventive Medicine and Public Health, University of Santiago de Compostela, A Coruña, Spain; ${ }^{3}$ Consortium for Biomedical Research in Epidemiology \& Public Health (CIBER en Epidemiología and Salud Pública/CIBERESP), Madrid, Spain; ${ }^{4}$ Population Screening Unit, Galician Regional Health Authority, Santiago de Compostela, Spain; ${ }^{5}$ Department of Oncology, Pontevedra University Hospital Complex, Pontevedra, Spain; ${ }^{6}$ Research Group for Health Promotion and Disease Prevention, Department of Public Health, University of Caldas, Manizales, Colombia; ${ }^{7}$ Scientific-Technical Advisory Unit, Galician Health Technology Assessment Agency, Health Knowledge Management Agency (Unidade de Asesoramento Científico-técnico/ avalia-t, Axencia de Coñecemento en Saúde/ACIS), Galician Regional Health Authority, Galicia, Spain; ${ }^{8}$ Department of Pneumology, A Coruña University Teaching Hospital Complex, A Coruña, Spain; ${ }^{9}$ Interdisciplinary Group of Research in Pulmonology, Health Research Institute of Santiago de Compostela (IDIS), Santiago de Compostela, Spain

Contributions: (I) Conception and design: A Casal-Mouriño, A Ruano-Ravina; (II) Administrative support: JM Barros-Dios, L Valdés-Cuadrado; (III) Provision of study materials or patients: A Casal-Mouriño, A Ruano-Ravina, M Lorenzo-González, Á Rodríguez-Martínez; (IV) Collection and assembly of data: JM Barros-Dios, L Valdés-Cuadrado; (V) Data analysis and interpretation: M Lorenzo-González, Á Rodríguez-Martínez, A Giraldo-Osorio, L Varela-Lema, T Pereiro-Brea, M Pérez-Ríos; (VI) Manuscript writing: All authors; (VII) Final approval of manuscript: All authors.

Correspondence to: Alberto Ruano-Ravina. Departamento de Medicina Preventiva y Salud Pública, Universidad de Medicina, C/San Francisco s/n, University of Santiago de Compostela, 15782, Santiago de Compostela, Spain. Email: alberto.ruano@usc.es.

\begin{abstract}
Stage III non-small cell lung cancer (NSCLC) includes a highly heterogeneous group of patients with differences in the extent and localization of disease. Many aspects of stage III disease are controversial. The data supporting treatment approaches are often subject to a number of limitations, due to the heterogeneous patient populations involved in the trials. Furthermore, the definition of stage III disease has changed over time, and early studies were frequently inadequately powered to detect small differences in therapeutic outcome, were not randomized, or had a limited follow-up times. Major improvements in therapy, including the use of more active chemotherapy agents and refinements in radiation and surgical techniques, also limit the interpretation of earlier clinical trials. Lastly, improvements in pretreatment staging have led to reclassification of patients with relatively minimal metastatic disease as stage IV rather than stage III, leading to an apparent increase in the overall survival of both stage III and IV patients. Median overall stage III NSCLC survival ranges from 9 to 34 months. Higher survival rates are observed in younger Caucasian women with good performance status, adenocarcinoma, mutations, stage IIIA, and in patients with multidisciplinary-team-based diagnoses.
\end{abstract}

Koywords: Lung cancer; staging; risk factors; histologic type; survival; incidence

Submitted Jan 19, 2020. Accepted for publication Mar 04, 2020.

doi: $10.21037 /$ tlcr.2020.03.40

View this article at: http://dx.doi.org/10.21037/tlcr.2020.03.40 


\section{Epidemiology}

\section{Definition and subtypes}

Lung cancer remains a leading cause of cancer incidence and mortality worldwide, in women and men alike, with more than 2 million newly diagnosed cases and 1.8 million deaths in 2018 , accounting for $18.4 \%$ of total cancer deaths (1). According to its histologic characteristics, lung cancer is divided into two categories, i.e., non-small cell lung cancer (NSCLC) and small cell lung cancer (SCLC). NSCLC accounts for more than $80 \%$ of all lung cancer cases (2). As reported by the Surveillance, Epidemiology and End Results (SEER) registry, incidence of NSCLC is 42.6 per 100,000 population (49.7 per 100,000 for men, and 37.2 per 100,000 for women, adjusted to the US standard population, 2011) (3).

Patients with NSCLC are commonly diagnosed at an advanced stage, either stage III or IV (4). Stage III NSCLC, also called "locoregionally or locally advanced disease", encompasses a group of heterogenous clinical conditions which differ widely in terms of disease extent and localization, and include patients with both potentially resectable and unresectable tumors (5).

Careful and accurate staging of NSCLC is critical to the therapeutic and prognostic implications for patients. The American Joint Committee on Cancer (AJCC) tumor, node and metastasis (TNM) staging system is the gold standard for classification of such tumors. The latest version of the AJCC staging manual is the $8^{\text {th }}$ edition, which was presented during the $16^{\text {th }}$ World Congress of Lung Cancer and has been in effect since January 2017 (6). Certain modifications have been made to this latest version in order to improve the prognostic capacity of the TNM classification, mainly by more clearly defining the position, size and nodal involvement in stage III NSCLC, and subclassifying stage III into sub-stages IIIA, IIIB and IIIC (7).

\section{Stage at diagnosis}

In accordance with the AJCC staging system, tumors classified as stage III, comprise tumors which vary widely in terms of size (T1-T4) and lymph node involvement (N0-N3). Stage IIIA includes smaller tumors (T1-T2) associated with ipsilateral bronchopulmonary, and hilar (N1) or mediastinal (N2) lymph node involvement, as well as large, locally invasive tumors (T3 or T4) when associated with $\mathrm{N} 0$ or N1. At the next level, stage IIIB includes tumors associated with spread to contralateral mediastinal or supraclavicular lymph nodes (N3), exactly like T3 or T4 tumors with N2 (8-10). Stage IIIC is a newly defined group in the TNM $8^{\text {th }}$ edition, which now encompasses patients with large tumors (T3 or T4) and N3 disease (11): these patients that are now classified as stage IIIC would have been ranked as stage IIIB under the previous classification.

As pointed out above, NSCLC is not usually diagnosed until advanced-stage disease is present. Approximately $20-35 \%$ of NSCLC cases will be diagnosed as stage III (6). Of the 813,302 newly diagnosed NSCLC patients recorded in the National Cancer DataBase (NCDB) from 1998 through 2006, $27.6 \%$ were found to be stage III and $65.1 \%$ were diagnosed as advanced disease (either stages III or IV), in line with data from other countries (12-15). During these years there was a progressive change in stage distribution, with an increase in stage IV NSCLC and a very slight decrease in stage III (from $28.6 \%$ in 1998 to $26.6 \%$ in 2006) (2).

Data from three different Australian cohorts show similar figures, with $23 \%$ of patients being diagnosed with stage III between 2001 and 2005, and a slight increase to $26 \%$ in the most recent cohort (2009-2013). Furthermore, there was also an increase in stage IV, with a total of $61 \%$ of patients being diagnosed at an advanced stage (III/IV) of the disease in the period from 2009 to 2013 (16). Similar data were reported by several European countries. In Spain, 28.4\% of NSCLC patients were diagnosed with stage III, with the respective proportions of the different sub-stages being as follows: $15.8 \%$ with stage IIIA; $11.6 \%$ with stage IIIB; and $1 \%$ with stage IIIC (17).

\section{Sex at diagnosis}

There are no differences by sex at diagnosis. A study conducted in Italy showed that data broken down by substage hardly differed by sex, with $12.7 \%$ of females and $10.7 \%$ of males being diagnosed with stage IIIA, and $14.3 \%$ of females and $15.7 \%$ of males being diagnosed with stage IIIB (18). Overall, $27 \%$ and $26.4 \%$ of males and females, respectively, were diagnosed with stage III. These data were comparable to those from other European countries, such as the United Kingdom (UK), Denmark, Sweden and Norway, with the percentage of patients diagnosed with stage III ranging from $24 \%$ to $30 \%$ (19). Data from a Canadian cohort show $19.7 \%$ of NSCLC patients as being diagnosed with stage III, with hardly any differences between the sexes (19.7\% males vs. $18.3 \%$ females). However, if patients diagnosed with stage IV are also considered, similar figures to the above countries are obtained, accounting for approximately $66 \%$ of all NSCLC patients $(20,21)$. 
Table 1 Characteristics of stage III patients (sourced from different studies)

\begin{tabular}{|c|c|}
\hline Variable & Results \\
\hline \multicolumn{2}{|l|}{ Sex } \\
\hline Women & $37-45.1 \%$ \\
\hline Men & $54.9-63 \%$ \\
\hline Median age at diagnosis & $65-79$ years old \\
\hline \multicolumn{2}{|l|}{ Smoking habit } \\
\hline Smoker or ex-smoker & $90 \%(\mathrm{PYI} \leq 40: 58 \%, \mathrm{PYI}>40: 42 \%)$ \\
\hline Never smoker & $4-11 \%$ \\
\hline \multicolumn{2}{|l|}{ Stage at diagnosis } \\
\hline \multicolumn{2}{|l|}{$7^{\mathrm{a}}$ TNM } \\
\hline IIIA & $44-61 \%$ \\
\hline IIIB & $50.6-56 \%$ \\
\hline \multicolumn{2}{|l|}{$8^{\mathrm{a}} \mathrm{TNM}$} \\
\hline IIIA & $76.20 \%$ \\
\hline IIIB & $22.90 \%$ \\
\hline IIIC & $0.90 \%$ \\
\hline \multicolumn{2}{|l|}{ Histologic type } \\
\hline Squamous cell & $30.7-78,9 \%$ \\
\hline Adenocarcinoma & $27.4-50 \%$ \\
\hline Large cell & $4.90 \%$ \\
\hline \multicolumn{2}{|l|}{ Mutations } \\
\hline EGFR & $33.50 \%$ \\
\hline ALK & $30.30 \%$ \\
\hline KRAS & $14.20 \%$ \\
\hline
\end{tabular}

\section{Age at diagnosis}

Median age at diagnosis of patients with stage III NSCLC ranged from 65 to 79 years (50.4\% of patients) (13). Recent studies have reported a median age at diagnosis of 67.4 years (with $39 \%$ of such cases aged $\leq 65$ years) (22). While $56.7 \%$ of 6,276 patients in Adizie et al.'s sample (21) were aged 65 to 80 years at diagnosis, Ryan et al. (23) observed a median age at diagnosis of 67.2 years. These results in terms of median age at diagnosis are similar to those obtained for the remaining NSCLC stages. Overall, median age at diagnosis among patients with NSCLC is 70 years for men and women alike (53\% of cases occur at ages $55-74$ years, and $37 \%$ at ages $>75$ years) (24). These data are in line with the SEER registry (3), which also shows a median age of 70 years at diagnosis, with the most frequent age range at diagnosis being 65 to 74 years. Athey et al. (25) report a median age of 68.3 to 73.2 years at diagnosis of NSCLC.

\section{Main risk factors: frequency of tobacco use and indoor radon}

Available results for stage III indicate that, on the whole, the distribution of risk factors at this stage is similar to that for lung cancer $(26,27)$. There is a high percentage of smokers, in that $58 \%$ of cases report tobacco use of $\leq 40$ packs/year and $42 \%$ report an even higher consumption. The percentage of never smoker patients with stage III is low, $4 \%$ to $11.1 \%$, depending on the study evaluated $(22,23)$. Around $90 \%$ of patients with stage III are smokers or ex-smokers at the date of diagnosis. Table 1 shows the specific characteristics of stage III NSCLC patients which may have an influence on their diagnosis.

With respect to residential radon, there are no published studies on its distribution by stage at diagnosis. Data obtained by our group on 174 patients diagnosed with lung cancer indicate that $17 \%$ had stages IIIA or IIIB, and exhibited median radon concentrations of 164 and $254 \mathrm{~Bq} / \mathrm{m}^{3}$ respectively. In both cases, these figures are higher than those registered by the general population. For stage IIIB, this concentration was higher than for the remaining stages at diagnosis (unpublished data).

\section{Histologic type at diagnosis}

Distribution of NSCLC cases by histologic lineage has varied across time. Overall, the predominant histologic type is currently adenocarcinoma (50\% of cases) (28). In stage III NSCLC cases, however, the most frequent histology was observed to vary according to the study evaluated, with adenocarcinoma and epidermoid cancer being the most frequent types. In a sample of 2,153 patients with stage III, Vinod et al. (13) describe $30.7 \%$ of cases with epidermoidtype lung cancer, $27.4 \%$ with adenocarcinoma, $4.9 \%$ with large cell lung cancer, $6 \%$ with other histologic types, and $31 \%$ without tumor filiation. The predominant histologic type in Ryan et al.'s study (23) was also epidermoid (48.2\% of cases). Other studies report that the most prevalent histologic type is adenocarcinoma (50\% of cases with stage III) (22), results similar to those observed for the other NSCLC stages.

Table 2 shows the distribution of histologic types in patients with stage III lung cancer. Although the trend, 
already reported by a number of studies, is towards adenocarcinoma increasing to become the leading histologic type, the majority of studies continue to show epidermoid carcinoma as the most frequent. This is likely due to the fact that some of the series are not current and therefore reflect older histologic patterns.

The Thoracic Tumor Registry (TTR) was recently set up in Spain to better understand the characteristics of patients with lung cancer, including aspects relating to its diagnosis, treatment and prognosis (17). Many other European countries (including the UK and The Netherlands) also have national registries but few have a collection of clinical data, thereby rendering inter-country comparisons impossible. The TTR compiled data on a total of 6,600 patients with NSCLC diagnosed between 2010 and 2018, $80 \%$ of whom presented with advanced disease (stage III or IV). The most common histologic type was adenocarcinoma (63.8\%), followed by epidermoid carcinoma $(27.7 \%)$ and large cell neuroendocrine carcinoma (3.1\%) (17). This study observed an increase in the frequency of adenocarcinoma, as envisaged by other American and European studies as well as the EUROCARE studies (34). The characteristics of patients with advanced $v s$. early stages are summarized in Table 3.

\section{Clinical characteristics of and therapeutic approach to stage III}

Stage III lung cancer is a highly heterogeneous stage that encompasses clinical profiles ranging from bulky-type lesions without lymph node involvement to multifocal lesions or small-sized lesions with extensive lymph node involvement (35).

It is common for patients presenting with symptoms to already have advanced forms of the disease. As many as $75 \%$ of patients may present with cough, chest pain, hemoptysis, weight loss or respiratory difficulty. Other symptoms, such as Horner syndrome, superior vena cava syndrome or paraneoplastic syndromes tend to be less frequent (36). Where disease is suspected, imaging and staging tests should be performed in line with the recommendations of the currently prevailing TNM lung cancer classification (7). While posteroanterior and lateral chest radiography is usually the first radiologic imaging to be performed, the imaging test of choice is computed tomography (CT) (37). This is why every patient with suspicion of lung cancer should undergo a CT scan of the chest and upper abdomen (36), which would allow for integrated evaluation of the lesion, along with any lymph node or metastatic involvement that may be present (38). Positron emission tomography (PET) is also used in diagnosis of NSCLC, thereby providing greater knowledge of the tumor metabolism (39). Most guidelines recommend early performance of PET to complete mediastinal staging (40), which, completed with the CT scan (PET/CT), not only enables better classification of lymph node involvement $(41,42)$ but has also assumed greater importance with the new TNM classification. Given the frequency of brain metastasis of lung cancer, it is considered advisable to rule out brain metastases through the use of magnetic resonance imaging (MRI) in such patients, with curative intent (43).

In line with the International Association for the Study of Lung Cancer (IASLC), American Thoracic Society (ATS) and European Respiratory Society (ERS) screening guidelines, the necessary histologic material should be obtained for tumor diagnosis and the potential study of mutations, which will be decisive when it comes to therapeutic management (7). To this end, the most frequent invasive tests for diagnosis would be flexible bronchoscopy, echobronchoscopy, transthoracic needle aspiration, surgical exploration (videothoracoscopy or open surgery), and pleural techniques (36).

In recent years, advances in the molecular characterization of lung cancer have revolutionized the classification, treatment and subsequent prognosis of these tumors. The study of biomarkers has become essential, particularly in advanced stages, and includes epidermal growth factor receptor (EGFR), anaplastic lymphoma kinase (ALK), Kirsten rat sarcoma viral oncogene homolog (KRAS), protooncogene B-RAF, human epidermal growth factor receptor 2 (HER2), receptor tyrosine kinase (ROS1), programmed death-ligand 1 (PD-L1), proto-oncogene tyrosine-protein kinase receptor Ret (RET), and hepatocyte growth factor receptor (MET) (17).

The role of multidisciplinary teams (MDT) is fundamental in disease management, in order to establish a clear diagnosis, perform staging, evaluate therapeutic options, and identify clinical trials that may benefit the patient, etc. Different reviews have shown that MDT-led management improves the quality of care, survival and quality of life of patients with stages III and IV. It is recommended that such committees include at least one pneumologist, one surgeon, one oncologist, one radiotherapist, one radiologist and one pathologist (40).

Improvements in the treatment of NSCLC have succeeded in increasing overall survival at 5 years of diagnosis from $9.4 \%$ in 2001 to $19.9 \%$ in 2016 . Treatment of stage 


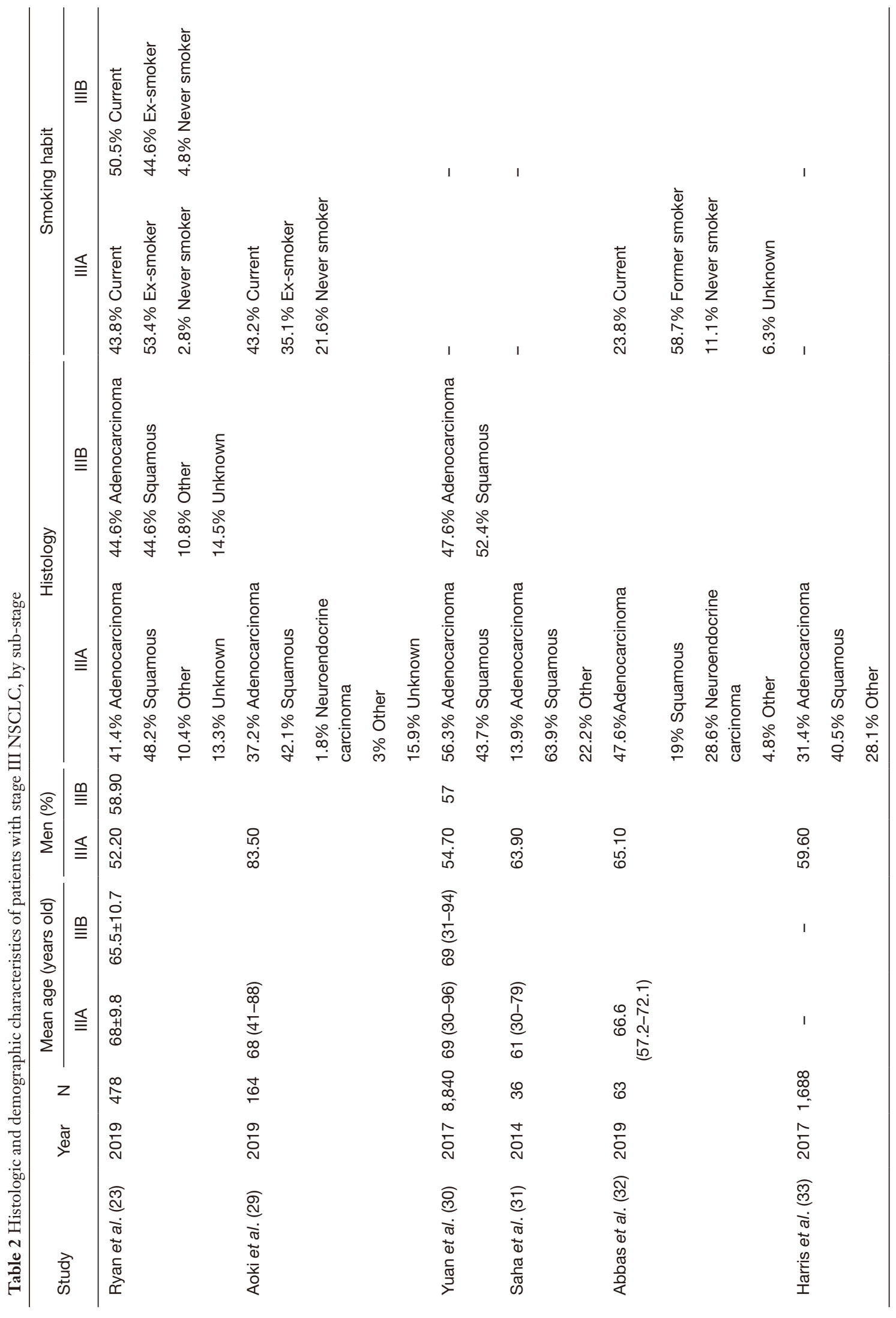


Table 3 Characteristics of lung cancer patients: comparison between advanced and localized stages (sourced from different studies)

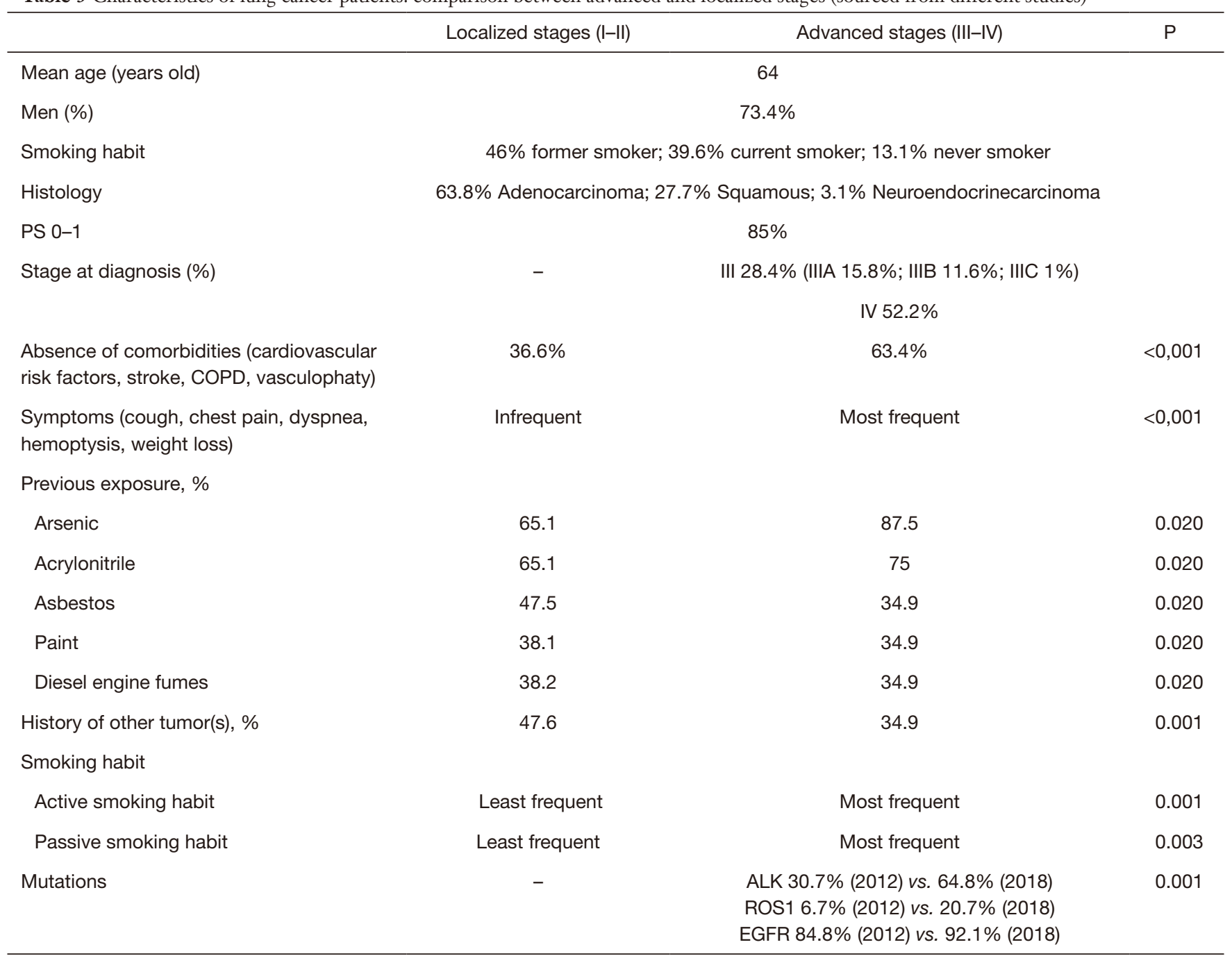

III NSCLC includes surgery, chemotherapy, radiotherapy and immunotherapy in different combinations. In stage IIIA, surgery is recommended, which may be followed by radiotherapy (especially, if $\mathrm{pN} 2$ ) or chemotherapy (if the patient has good performance status). In unresectable cases, the use of concomitant chemoradiotherapy with curative intent is recommended, followed by immunotherapy (durvalumab: for locally advanced cases that have shown no progress with chemotherapy).

\section{Markers and mutations in stage III}

As mentioned above, identification of new molecular targets has amounted to a 'before and after' in the prognosis and treatment of patients with NSCLC. This has set new diagnostic and therapeutic standards, especially in stage IV, but also in stage III.

The presence of specific mutations follows a similar distribution, independently of NSCLC stage. Overall, the presence of EGFR mutations is observed to vary with the study population, and ranges from $15 \%$ through $62 \%$ (higher frequency in never smokers, pulmonary adenocarcinoma and Asian populations) (44). ALK rearrangements are less frequent (4\% of cases with pulmonary adenocarcinoma, fundamentally in young never smokers), as are KRAS rearrangements (19\% of cases).

The specific panorama of mutations and targeted therapy in stage III is analyzed below.

Despite the important benefit of tyrosine kinase inhibitor (TKI) therapy (erlotinib, gefitinib, afatinib, osimertinib) in 
stage IV in the case of patients with EGFR gene mutations, there is no evidence of this option having a greater benefit than the treatment of choice, chemoradiotherapy with or without surgery, with or without immunotherapy, in stage III. The latest European Society of Medical Oncology (ESMO) (45) guidelines do not recommend targeted therapy in stage III. This recommendation is based on the SWOG S0023 study (46), which reported lower overall survival in patients with EGFR gene mutations who received anti-EGFR therapy, in comparison with placebo after chemoradiotherapy. Furthermore, they highlight the fact that adjuvant treatment at early stages has also failed to show any benefit (47).

According to the systematic review published by Desai et al. (48), however, TKI-EGFR targeted therapy in combination with chemoradiotherapy did show a benefit in patients with EGFR gene mutations. These results were based on analyses of 8 studies - most of which were phaseII, non-randomized, and with small-sized samples—-so that there is a need for more and better studies to be conducted to analyze the concrete benefit of this option.

The role of neoadjuvant erlotinib was recently analyzed in a meta-analysis of patients with stage III-N2 (30), and showed longer progression-free survival and a higher pathological response rate than did chemotherapy in patients with mutant tumors. Insofar as adjuvancy is concerned, this has proved to be of benefit in progressionfree survival in stages II-IIIA NSCLC (30).

It should be highlighted that immunotherapy studies suggest a decrease in the efficacy of this treatment in patients with EGFR gene mutations (49). In contrast, the PACIFIC study (50) has reported the benefit of treatment with antiPD-L1 (durvalumab) therapy as maintenance after treatment with chemoradiotherapy in patients with inoperable stage III NSCLC, including the subset of patients with EGFR gene mutations in the analysis, without any detriment to the benefit for the latter, though it has to be said that the number of patients with mutations was small (6\%). Indeed, it was the PACIFIC study that established consolidation immunotherapy in inoperable stage III NSCLC, after chemoradiotherapy (50). It showed an increase in overall survival, without differences in progression-free survival, though with a longer diseasefree interval to distant recurrence or death. Subsequent retrospective analyses were performed to compare efficacy by reference to PD-L1 expression levels, though no differences in benefit were observed, thus suggesting that maintenance therapy with durvalumab would be indicated for all PD-L1 expression levels (51).
Studies are currently being undertaken which analyze the benefit of treatment with immuno-chemoradiotherapy. In addition, there are multiple ongoing studies which analyze adjuvant immunotherapy (nivolumab, pembrolizumab, ipilimumab, atezolizumab) in inoperable NSCLC, as reported by Jain et al.'s review (52) of immunotherapy status in stage III, published in June 2019.

Hence, despite having altered the therapeutic and prognostic algorithm with notable benefit for NSCLC patients with metastatic disease, there is still a need for more studies that would help understand mutations and the benefit of targeted treatment, as well as the differences in terms of progress and prognosis in patients with stage III NSCLC.

\section{Survival}

\section{Stage III lung cancer: survival and time trends}

According to the SEER database 3), 5-year relative survival among US patients with NSCLC has been steadily increasing since the creation of these records, ranging from $16.4 \%$ for patients diagnosed between $1975-1977$ to $25.1 \%$ for patients diagnosed between 2009-2015 (3). Based on the analysis of the 1,150,722 NSCLC incident cases included in the USNCDB from 2004 through 2013, 4-year overall survival (OS) for NSCLC has improved significantly for persons diagnosed in 2004-2009 in comparison with those diagnosed in 2010 2013 (23.4\% vs. $25.2 \%, \mathrm{P}<0.0001)$ (53). The improvement in survival was reported to be more pronounced for early than later stages, as evidenced by the hazard ratios for OS for stage $\mathrm{I}(0.8, \mathrm{P}<0.0001)$ and stage IV $(0.86, \mathrm{P}<0.0001)(53)$. For the 4,564 patients with unresectable stage III NSCLC included in the SEER database across the period 2009 through 2014, no significant differences in 1-year OS were found between patients initiating chemoradiotherapy in 2009-2010 and those initiating it in 2011-2012 or 2013-2014 (56\% vs. 58\%, $\mathrm{P}=0.827$ ) (54).

There are few data on NSCLC survival patterns in other countries. We identified a publication analyzing two comparative prospective multicenter epidemiological studies (KBP-CPHG studies) conducted in French hospitals during 2000 and 2010 (55). These studies showed that overall 5 -year survival increased from $11.4 \%$ in 2000 to $13.8 \%$ in 2010 . This improvement was independent of the changes in tumor characteristics.

The SEER database results show an overall 5-year survival rate of $34.5 \%$ (for patients included between 
2009 and 2015, and followed up until 2016). There were differences by gender, with 5 -year survival for regional disease being $29.9 \%$ in males $v s .39 .7 \%$ in females (3).

\section{Stage III lung cancer: 1-, 3- and 5-year survival}

To assess stage III NSCLC survival, data can be sourced from clinical trials or population-based studies. Although the impact of different treatments on survival is assessed in all of the studies identified, summarizing the overall survival data is not possible due to the high degree of heterogeneity of the patients and treatments included.

The analysis of the Veterans Affairs Central Cancer Registry records on 1,842 patients diagnosed from October 2001 through December 2010 showed a median overall survival of 17.3 months among patients treated with concurrent radiation and etoposide/cisplatin, and 14.6 months among those treated with concurrent radiation and carboplatin/paclitaxel (56).

According to the analysis of the 4,564 patients with unresected stage III NSCLC who were identified through the SEER Medicare-linked database (patients aged $\geq 65$ years diagnosed from 2009 through 2014), median OS was 13.2 months for patients initiating treatment with chemotherapy and 14.8 months for those initiating treatment with radiochemotherapy (54). In a previous study based on SEER data (patients aged $\geq 65$ years diagnosed across the period 2002-2009), medium OS was found to be 18 months for patients with concurrent chemoradiation alone and 21 months for concurrent consolidation chemotherapy regimens (33).

Urvay et al. retrospectively reviewed the clinical records of 148 patients with advanced inoperable stage IIIA or IIIB NSCLC diagnosed from 2007 through 2015 in Turkey, who had undergone concurrent or sequential chemoradiation, and estimated median survival as being 19 months and overall 3 -year survival as being $27 \%$ (57). Similar results were obtained after the analysis of a retrospective cohort that comprised 165 Brazilian patients treated with chemoradiation therapy followed by consolidated chemotherapy, in which the median OS was 9 months, and the 1-, 2- and 3-year survival rates were $64.8 \%, 45.5 \%$ and $32.2 \%$, respectively (58). OS did not differ among patients who received consolidated therapy (23 vs. 18 months; $\mathrm{P}=0.128$ ).

\section{Differential characteristics in stage III survival}

Median OS of patients with stage III ranges from 9 to
34 months depending on the study evaluated. Table 4 shows median survival observed in some studies. This variation is due to the fact that each paper evaluates a specific subset of patients with stage III.

With respect to survival by sex, this appears to be higher in women regardless of stage at diagnosis. Median survival of stage III patients was 12 months (95\% CI, 11.1-12.9 months) for women and 9 months (95\% CI, 8.3-9.7 months) for men (13). Similarly, Käsmann et al. (22) report a higher percentage survival at 3 -years of diagnosis in women $(\mathrm{P}=0.007)$.

Survival by age at diagnosis shows that the youngest patients experience better survival as compared with cases that are older at diagnosis, results comparable with those obtained for stage III. For all stages, US data show overall survival at 5 years of diagnosis in patients aged under 45 years as being $34.6 \%$ ( $18.1 \%$ if aged $>65$ years). Median survival and percentage survival at 3 years of diagnosis for cases aged $<50$ years with stage III was 15 months (95\% CI, 11.6-18.4 months) and 21.8\%, respectively; in comparison, the equivalent figures for patients diagnosed at age $\geq 80$ years were median survival of 7 months ( $95 \%$ CI, 5.8-8.2 months) and percentage survival at 3 years of $6.3 \%(\mathrm{P}<0.001)(13)$. Adizie et al. (21) describe a higher one-year survival rate in the group of patients aged $<65$ years than in the group aged $>80$ years $(44 \%$ and $21.6 \%$, respectively). In their study, however, Käsmann et al. (22) included 99 patients with stage III, without observing any statistically significant differences by age at diagnosis in percentage survival at one and 3 years of diagnosis, i.e., age $\leq 65$ years: $69 \%$ and $36 \%$, and age $>65$ years: $80 \%$ and $28 \%$, respectively $(\mathrm{P}=0.348)$.

There are few studies that analyze survival by race. Overall, the SEER shows survival at 5 years in the white and black races as being $20.3 \%$ and $17.8 \%$, respectively. In their study, Zhang et al. (59) report a better survival rate in the Caucasian population with stage III NSCLC, with a $12 \%$ relative reduction in risk of death.

The best overall survival by histology in NSCLC is obtained for pulmonary adenocarcinoma, which also occurs in cases with stage III. When median survival and survival at 3 years of diagnosis were evaluated by histologic lineage in stage III, the following results were obtained: 13 months and $19.2 \%$ for adenocarcinoma; 10 months and $12.5 \%$ for epidermoid cancer; and 9 months and $15.3 \%$ for large cell lung cancer $(\mathrm{P}<0.001)(13)$. Even so, there are papers that report no differences in stage IIIA survival by histology, with a median survival of 20.9 and 18.9 months for adenocarcinoma and epidermoid cancer, respectively 
Table 4 Stage III-NSCLC survival (median, 1, 3 and 5-year survival)

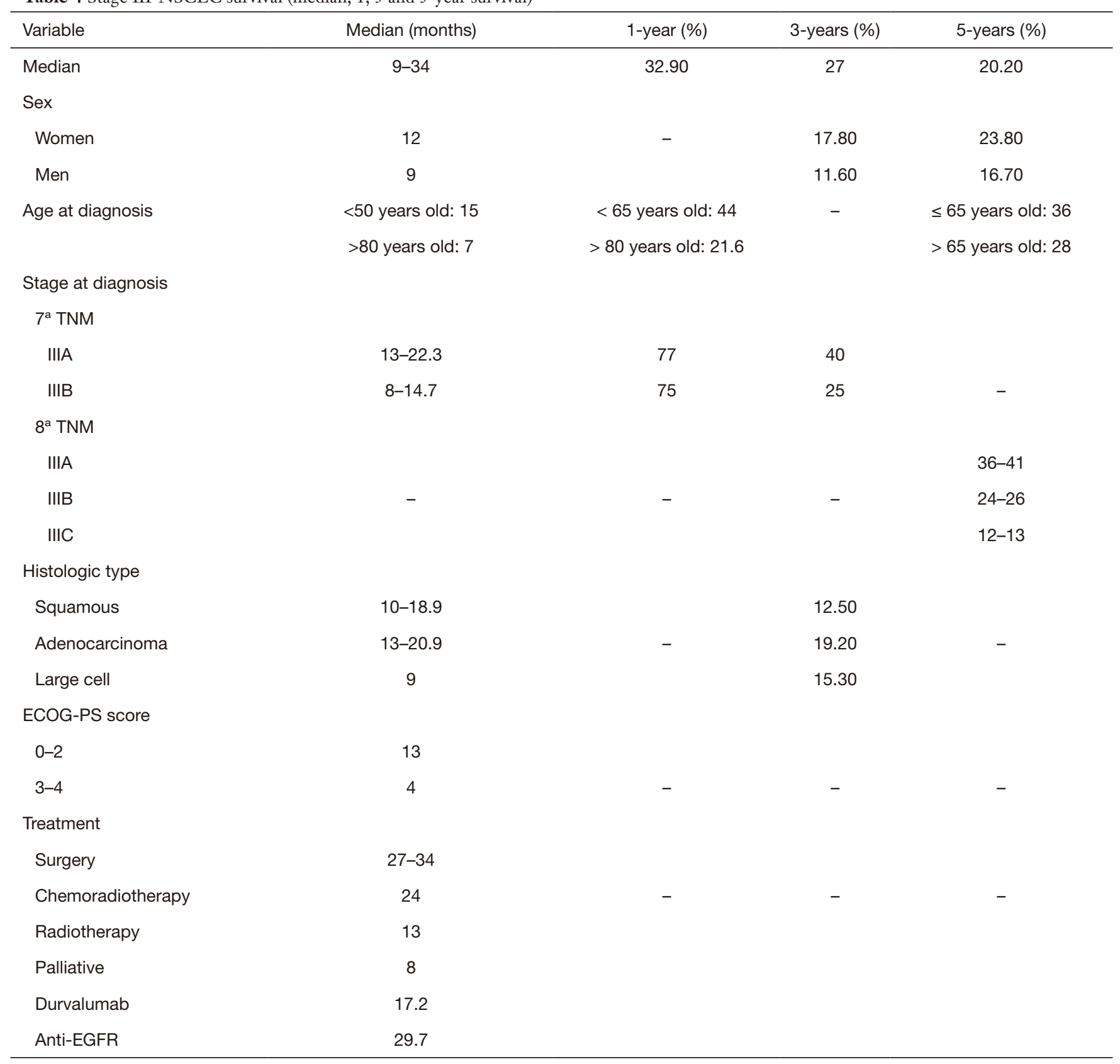

NSCLC, non-small cell lung cancer.

$(\mathrm{P}=0.244)(23)$.

As mentioned above, the definition of stage III has varied over time. The $7^{\text {th }}$ TNM classification divides cases into stage IIIA and stage IIIB, with lower survival for patients in the latter group (13 vs. 8 months, respectively: $\mathrm{P}<0.001)$ (13). Once again, however, there are some papers that do not report statistically significant differences in percentage survival at 1 and 3 years of diagnosis, with figures of $77 \%$ and $40 \%$ for stage IIIA, and $75 \%$ and $25 \%$ for stage IIIB $(\mathrm{P}=0.23)$ (22). Ryan et al. (23) describe median survival in stages IIIA and IIIB of 22.3 and 14.7 months, respectively $(\mathrm{P}=0.148)$. Taking the $8^{\text {th }}$ TNM classification into account, 
it would seem that the lower the sub-stage the better the survival, with percentage survival rates at 5 -year of diagnosis in stages IIIA, IIIB and IIIC of $36 \%, 26 \%$ and $13 \%$, respectively. Similarly, Goldstraw et al. (7) report survival at 5 -years in stages IIIA, IIIB and IIIC of $41 \%, 24 \%$ and $12 \%$, respectively.

Performance status measured by validated scales (ECOG-PS) is known to be an important prognostic factor for all NSCLC stages. Patients with inoperable stage III with good performance status (ECOG-PS 0-1) should receive treatment with chemoradiotherapy, followed by immunotherapy (anti-PD-L1) (50). In this subset of patients, the lower the ECOG-PS score, the better the survival (ECOG-PS 0-2: median survival of 13 months; and ECOG-PS 3-4: 4 months, $\mathrm{P}<0.001)(13)$. Käsmann et al. (22) evaluated a total of 99 patients with inoperable stage III, who had a median survival of 26.4 months where the ECOG-PS score was 0 , and 18.9 months in those cases where the ECOG-PS score was 1. Accordingly, the best survival rate is to be found in the group of younger patients (age $<65$ years) with stage IIIA and ECOG-PS 0-1, namely, $54.5 \%$ survival at one year of diagnosis (21).

Median survival of patients with stage III appears to be higher in surgical cases with respect to other treatment modalities, with rates of 27 to 34 months for cases undergoing surgery, 24 months (95\% CI, 20.6-27.4 months) for the chemoradiotherapy group, 13 months (95\% CI, 8.3-17.7 months) for isolated radiotherapy, and 8 months (95\% CI, 7.5-8.5 months) for cases with palliative treatment (13). Percentage survival at 5 years of diagnosis in the group of patients who received concomitant treatment with chemoradiotherapy was $20 \%(60)$. However, if only the outcomes of the oldest population (age $>70$ years) are taken into account, no statistically significant differences are observed by type of treatment used, with median survival of 21.1 months for those who received chemoradiotherapy and 18.1 months for the isolated radiotherapy group $(\mathrm{P}=0.220)$ (61). Likewise, there are no significant differences between patients in stage III who receive isolated chemoradiotherapy or chemoradiotherapy, followed by surgery (62).

\section{Concluding remarks}

Stage III NSCLC includes a highly heterogeneous group of patients with differences in disease extent and localization. Many aspects of the epidemiology of specific patient subsets are thus subject to a series of limitations, such as the fact that: the trials involved heterogeneous patient populations; the definition of stage III disease has changed over time; and early studies were frequently inadequately powered to detect small differences in therapeutic outcome, were not randomized, or had a limited duration of follow-up.

Median overall stage III survival is estimated to lie somewhere between 9 and 34 months. Studies that report survival data at five years broken down by the three sub-stages are still relatively few and with limited sample sizes. The best survival figures are obtained for young Caucasian women with good performance status, pulmonary adenocarcinoma (above all without the presence of mutations), in stage IIIA, and those cases where the diagnosis is made by a multidisciplinary committee. Age at diagnosis is similar to that for other lung cancer stages, as is distribution by sex and histologic stage. There are hardly any studies that have analyzed the influence of tobacco use or residential radon on stage III survival, with further studies thus being needed to address this aspect.

\section{Acknowledgments}

Funding: None.

\section{Footnote}

Provenance and Peer Review: This article was commissioned by the Guest Editor (Mariano Provencio) for the series "Multimodal management of locally advanced N2 nonsmall cell lung cancer" published in Translational Lung Cancer Research. The article has undergone external peer review.

Conflicts of Interest: All authors have completed the ICMJE uniform disclosure form (available at http://dx.doi. org/10.21037/tlcr.2020.03.40). The series "Multimodal management of locally advanced N2 non-small cell lung cancer" was commissioned by the editorial office without any funding or sponsorship. The authors have no other conflicts of interest to declare.

Ethical Statement: The authors are accountable for all aspects of the work in ensuring that questions related to the accuracy or integrity of any part of the work are appropriately investigated and resolved.

Open Access Statement: This is an Open Access article distributed in accordance with the Creative Commons Attribution-NonCommercial-NoDerivs 4.0 International 
License (CC BY-NC-ND 4.0), which permits the noncommercial replication and distribution of the article with the strict proviso that no changes or edits are made and the original work is properly cited (including links to both the formal publication through the relevant DOI and the license). See: https://creativecommons.org/licenses/by-nc$\mathrm{nd} / 4.0 /$.

\section{References}

1. Bray F, Ferlay J, Soerjomataram I, et al. Global cancer statistics 2018: GLOBOCAN estimates of incidence and mortality worldwide for 36 cancers in 185 countries. CA Cancer J Clin 2018;68:394-424.

2. Oser MG, Niederst MJ, Sequist LV, et al. Transformation from non-small-cell lung cancer to small-cell lung cancer: molecular drivers and cells of origin. Lancet Oncol 2015;16:165-72.

3. Surveillance, Epidemiology, and End Results (SEER) Program. May 2015. Available online: http://seer.cancer.gov/

4. Siegel RL, Miller KD, Jemal A. Cancer statistics, 2018. CA Cancer J Clin 2018;68:7-30.

5. National Comprehensive Cancer Network. NCCN Clinical Practice Guidelines in Oncology: Non-Small Cell Lung Cancer. V. 2. Dec 2014. Available online: http:// www.nccn.org/professionals/physician_gls/PDF/nscl.pdf

6. The American Joint Committee on Cancer. AJCC Cancer Staging Manual. 8th ed. 2017.

7. Goldstraw P, Chansky K, Crowley J, et al. International Association for the Study of Lung Cancer Staging and Prognostic Factors Committee, Advisory Boards, and Participating Institutions; International Association for the Study of Lung Cancer Staging and Prognostic Factors Committee Advisory Boards and Participating Institutions. The IASLC Lung Cancer Staging Project: proposals for revision of the TNM stage groupings in the forthcoming (eighth) edition of the TNM classification for lung cancer. J Thorac Oncol 2016;11:39-51.

8. Rami-Porta R, Bolejack V, Crowley J, et al. IASLC Staging and Prognostic Factors Committee, Advisory Boards and Participating Institutions. The IASLC Lung Cancer Staging Project: proposals for the revisions of the T descriptors in the forthcoming eighth edition of the TNM classification for lung cancer. J Thorac Oncol 2015;10:990-1003.

9. Asamura H, Chansky K, Crowley J, et al. International Association for Study of Lung Cancer Staging and Prognostic Factors Committee, Advisory Board Members, and Participating Institutions. The IASLC Lung Cancer
Staging Project: proposals for the revision of the $\mathrm{N}$ descriptors in the forthcoming eighth edition of the TNM classification of lung cancer. J Thorac Oncol 2015;10:1675-84.

10. Eberhardt WE, Mitchell A, Crowley J, et al. International Association for Study of Lung Cancer Staging and Prognostic Factors Committee, Advisory Board Members, and Participating Institutions. The IASLC Lung Cancer Staging Project: proposals for the revision of the $M$ descriptors in the forthcoming eighth edition of the TNM classification of lung cancer. J Thorac Oncol 2015;10:1515-22.

11. Rami-Porta R, Asamura H, Travis WD, et al. Lung cancer - major changes in the American Joint Committee on Cancer eighth edition cancer staging manual. CA Cancer J Clin 2017;67:138-55.

12. Morgensztern D, Ng SH, Gao F, et al. Trends in Stage Distribution for Patients with Non-small Cell Lung Cancer. A National Cancer Database Survey. J Thorac Oncol 2010;5:29-33.

13. Vinod SK, Wai E, Alexander C, et al. Stage III NonSmall-Cell Lung Cancer Population-Based Patterns of Treatment in British Columbia, Canada. J Thorac Oncol 2012;7:1155-63.

14. Sutandyo N, Suratman E. Non-Small Cell Lung Carcinoma in Women: A Retrospective Cohort Study in Indonesia. Acta Med Indones 2018;50:291-8.

15. Wainer Z, Wright GM, Gough K, et al. Sex-Dependent Staging in Non-Small Cell Lung Cancer; Analysis of the Effect of Sex Differences in the Eighth Edition of the Tumor, Node, Metastases Staging System. Clin Lung Cancer 2018;19:e933-44.

16. Denton EJ, Hart D, Waiter Z, et al. Changing trends in diagnosis, staging, treatment and survival in lung cancer: comparison of three consecutive cohorts in an Australian lung cancer centre. Intern Med J 2016;46:946-54.

17. Provencio M, Carcereny E, Rodríguez-Abreu D, et al. Lung cancer in Spain: information from the Thoracic Tumors Registry (TTR study). Transl Lung Cancer Res 2019;8:461-75.

18. Landi MT, Consonni D, Rotunno M, et al. Environment And Genetics in Lung cancer Etiology (EAGLE) study: An integrative population-based case-control study of lung cancer. BMC Public Health 2008;8:203.

19. Walters S, Maringe C, Coleman MP, et al. Lung cancer survival and stage at diagnosis in Australia, Canada, Denmark, Norway, Sweden and the UK: a populationbased study, 2004-2007. Thorax 2013;68:551-64. 
20. Canadian Cancer Statistics. A 2018 special report on cancer incidence by stage.

21. Adizie JB, Khakwani A, Beckett P, et al. Stage III Nonsmall Cell Lung Cancer Management in England. Clin Oncol (R Coll Radiol) 2019;31:688-96.

22. Käsmann L, Taugner J, Eze C, et al. Performance Status and Its Changes Predict Outcome for Patients With Inoperable Stage III NSCLC Undergoing Multimodal Treatment. Anticancer Res 2019;39:5077-81.

23. Ryan KJ, Skinner KE, Fernandes AW, et al. Real-world outcomes in patients with unresected stage III non-small cell lung cancer. Med Oncol 2019;36:24.

24. de Groot PM, Wu CC, Carter BW, et al. The epidemiology of lung cancer. Transl Lung Cancer Res 2018;7:220-33.

25. Athey VL, Walters SJ, Rogers TK. Symptoms at lung cancer diagnosis are associated with major differences in prognosis. Thorax 2018;73:1177-81.

26. Khuder SA. Effect of cigarette smoking on major histological types of lung cancer: a meta-analysis. Lung Cancer 2001;31:139-48.

27. Jenks S. Is lung cancer incidence increasing in neversmokers? J Natl Cancer Inst 2015;108:3-4.

28. Janssen-Heijnen ML, Coebergh JW, Klinkhamer PJ, et al. Is there a common etiology for the rising incidence of and decreasing survival with adenocarcinoma of the lung? Epidemiology 2001;12:256.

29. Aoki T, Akiba T, Nishiyama J, et al. Analysis of key clinical features for achieving complete remission in stage III and IV non-small cell lung cancer patients. Respir Res 2019;20:263.

30. Yuan Y, Huang Q, Gu C, et al. Disease-free survival improved by use of adjuvant EGFR tyrosine kinase inhibitors in resectable non-small cell lung cancer: an updated meta-analysis. J Thorac Dis 2017;9:5314-21.

31. Saha SP, Kalathiya RJ, Davenport DL, et al. Survival after Pneumonectomy for Stage III Non-small Cell Lung Cancer. Oman Med J 2014;29:24-7.

32. Abbas MN, Ayoola A, Padman S, et al. Survival and late toxicities following concurrent chemo-radiotherapy for locally advanced stage III non-small cell lung cancer: findings of a 10-year Australian single centre experience with long term clinical follow up. J Thorac Dis 2019;11:4241-8.

33. Harris JP, Patel MI, Loo BW, et al. A population-based comparative effectiveness study of chemoradiation regimens and sequences in stage III non-small cell lung cancer. Lung Cancer 2017;108:173-82.
34. Stellman SD, Muscat JE, Thompson S, et al. Risk of squamous cell carcinoma and adenocarcinoma of the lung in relation to lifetime filter cigarette smoking. Cancer 1997;80:382-8.

35. Makimoto G, Hotta K, Kiura K. Recent trends in the treatment of unresectable stage III non-small-cell lung cancer. Respir Investig 2019;57:330-6.

36. Gridelli C, Rossi A, Carbone DP, et al. Non-small-cell lung cancer. Nat Rev Dis Primers 2015;1:15009.

37. Spiro SG, Gould MK, Colice GL, et al. Initial evaluation of the patient with lung cancer: symptoms, signs, laboratory tests, and paraneoplastic syndromes: ACCP evidenced-based clinical practice guidelines ( 2 nd edition). Chest 2007;132:149S-60S.

38. ESTS - Sociedad Europea de Cirujanos Torácicos - Libro de texto [Internet]. [cited 25 November 2019]. Available online: http://www.ests.org/textbook

39. Antoch G, Stattaus J, Nemat AT, et al. Non-small cell lung cancer: dual-modality PET/CT in preoperative staging. Radiology 2003;229:526-33.

40. Parente P, Chan BA, Hughes BGM, et al. Patterns of care for stage III non-small cell lung cancer in Australia. Asia Pac J Clin Oncol 2019;15:93-100.

41. Fischer BM, Mortensen J, Hansen H, et al. Multimodality approach to mediastinal staging in non-small cell lung cancer. Faults and benefits of PET-CT: a randomised trial. Thorax 2011;66:294-300.

42. Saettele TM, Ost DE. Multimodality systematic approach to mediastinal lymph node staging in non-small cell lung cancer. Respirology 2014;19:800-8.

43. Postmus PE, Kerr KM, Oudkerk M, et al. Early and locally advanced non-small-cell lung cancer (NSCLC): ESMO Clinical Practice Guidelines for diagnosis, treatment and follow-up. Ann Oncol 2017;28:iv1-21.

44. Shi Y, Au JS, Thongprasert S, et al. A prospective, molecular epidemiology study of EGFR mutations in Asian patients with advanced non-small-cell lung cancer of adenocarcinoma histology (PIONEER). J Thorac Oncol 2014;9:154-62.

45. Eberhardt WEE, De Ruysscher D, Weder W, et al. 2nd ESMO Consensus Conference in Lung Cancer: locally advanced stage III non-small-cell lung cancer. Ann Oncol 2015;26:1573-88.

46. Kelly K, Chansky K, Gaspar LE, et al. Phase III trial of maintenance gefitinib or placebo after concurrent chemoradiotherapy and docetaxel consolidation in inoperable stage III non-small-cell lung cancer: SWOG S0023. J Clin Oncol 2008;26:2450-6. 
47. Goss GD, O'Callaghan C, Lorimer I, et al. Gefitinib versus placebo in completely resected non-small-cell lung cancer: results of the NCIC CTG BR19 study. J Clin Oncol 2013;31:3320-6.

48. Desai S, Kim C, Veytsman I. Role of Anti-EGFR Targeted Therapies in Stage III Locally Advanced Non-small Cell Lung Cancer: Give or Not to Give? Curr Oncol Rep 2019;21:84.

49. Lee CK, Man J, Lord S, et al. Clinical and Molecular Characteristics Associated With Survival Among Patients Treated With Checkpoint Inhibitors for Advanced NonSmall Cell Lung Carcinoma: A Systematic Review and Meta-analysis. JAMA Oncol 2018;4:210.

50. Antonia SJ, Villegas A, Daniel D, et al. durvalumab after Chemoradiotherapy in Stage III Non-Small-Cell Lung Cancer. N Engl J Med 2017;377:1919-29.

51. Melosky B, Juergens R, McLeod D, et al. Immune checkpoint-inhibitors and chemoradiation in stage III unresectable non-small cell lung cancer. Lung Cancer 2019;134:259-67.

52. Jain NA, Otterson GA. Immunotherapy in inoperable stage III non-small cell lung cancer: a review. Drugs Context 2019;8:212578.

53. Lou Y, Dholaria B, Soyano A, et al. Survival trends among non-small-cell lung cancer patients over a decade: impact of initial therapy at academic centers. Cancer Med 2018;7:4932-42.

54. Bobbili P, Ryan K, Duh MS, et al. Treatment patterns and overall survival among patients with unresectable, stage III non-small-cell lung cancer. Future Oncol 2019;15:3381-93.

55. Debieuvre D, Locher C, Asselain B, et al. Evidence of slight improvement in five-year survival in non-small cell lung cancer over the last 10 years: Results of the French KBP-CPHG real-world studies. Bull Cancer
2019;106:283-92.

56. Santana-Davila R, Devisetty K, Szabo A, et al. Cisplatin and etoposide versus carboplatin and paclitaxel with concurrent radiotherapy for stage III non-small-cell lung cancer: an analysis of Veterans Health Administration data. J Clin Oncol 2015;33:567-74.

57. Urvay SE, Yucel B, Erdis E, et al. Prognostic Factors in Stage III Non-Small-Cell Lung Cancer Patients. Asian Pac J Cancer Prev 2016;17:4693-7.

58. Cordeiro de Lima VC, Baldotto CS, Barrios CH, et al. Stage III Non-Small-Cell Lung Cancer Treated With Concurrent Chemoradiation Followed or Not by Consolidation Chemotherapy: A Survival Analysis From a Brazilian Multicentric Cohort. J Glob Oncol 2018;4:1-11.

59. Zhang H, Zhang DX, Ju T, et al. The effect of postoperative radiotherapy on the survival of patients with resectable stage III-N2 non-small-cell lung cancer: a systematic review and meta-analysis. Neoplasma 2019;66:717-26.

60. Hanna N, Neubauer M, Yiannoutsos C, et al. Phase III study of cisplatin, etoposide, and concurrent chest radiation with or without consolidation docetaxel in patients with inoperable stage III non-small-cell lung cancer: the Hoosier Oncology Group and U.S. Oncology. J Clin Oncol 2008;26:5755-60.

61. Kim DY, Song C, Kim SH, et al. Chemoradiotherapy versus radiotherapy alone following induction chemotherapy for elderly patients with stage III lung cancer. Radiat Oncol J 2019;37:176-84.

62. Swaminath A, Vella ET, Ramchandar K, et al. Surgery after chemo NSCLC radiotherapy in patients with stage III (N2 or N3, excluding T4) non-small-cell lung cancer: a systematic review. Curr Oncol 2019;26:e398-404.
Cite this article as: Casal-Mouriño A, Ruano-Ravina A, Lorenzo-González M, Rodríguez-Martínez Á, Giraldo-Osorio A, Varela-Lema L, Pereiro-Brea T, Barros-Dios JM, Valdés-Cuadrado L, Pérez-Ríos M. Transl Lung Cancer Res 2021;10(1):506-518. doi: 10.21037/tlcr.2020.03.40 